\title{
Independence of first- and second-order memories in newborn rabbits
}

\author{
Gérard Coureaud, ${ }^{1,3}$ Solène Languille, ${ }^{2}$ Virginie Joly, ${ }^{1}$ Benoist Schaal, ${ }^{1}$ and Bernard Hars ${ }^{2}$ \\ ${ }^{1}$ Equipe Ethologie Développementale et Psychologie Cognitive, Centre des Sciences du Goût et de I'Alimentation, UMR 6265 \\ CNRS/INRA/Université de Bourgogne/Agrosup Dijon, 21000 Dijon, France; ${ }^{2}$ Laboratoire de Neurobiologie de I'Apprentissage, de la \\ Mémoire et de la Communication, UMR 8620 CNRS, Université Paris XI, 91405 Orsay, France
}

\begin{abstract}
The mammary pheromone promotes the acquisition of novel odorants (CSI) in newborn rabbits. Here, experiments pinpoint that CS1 becomes able to support neonatal learning of other odorants (CS2). We therefore evaluated whether these first- and second-order memories remained dependent after reactivation. Amnesia induced after CS2 recall selectively blocked this memory, when recall and amnesia of CS1 left the souvenir of CS2 safe; this finding partially differed from results obtained in adult mammals. Thus, in this model of neonatal appetitive odor learning, second-order memory seems to depend on first-order memory for its formation but not for its maintenance.
\end{abstract}

The mammary pheromone (MP) emitted by lactating rabbit females helps newborn rabbits to orient to the mother, then rapidly to localize and grasp the nipples (Coureaud 2001; Schaal et al. 2003). It is a determinant for survival and growth in the context of mother-young interactions daily limited ( $<5 \mathrm{~min}$ ) (Zarrow et al. 1965). The MP also acts as a cognitive organizer promoting the rapid (single trial) appetitive learning of new odor stimuli, initially neutral. After pairing with the MP, the learned stimulus gains significance (i.e., releases the sucking behavior of neonates) in less than $24 \mathrm{~h}$, following rules of first-order conditioning where the MP constitutes the unconditioned stimulus (US) and the novel odorant the conditioned one (CS1) (Coureaud et al. 2006, 2008, 2009).

Consolidation and reconsolidation processes, usually required in long-term memories (McGaugh 1966, 2000; Nader et al. 2000b; Sara 2000), are also involved in MP-induced odor memory; retention is impaired by injection of a protein synthesis inhibitor (anisomycin), and anisomycin induces amnesia also after reactivation of the previously consolidated memory (Coureaud et al. 2009). Nevertheless, properties of learning and memory promoted by the MP remain poorly known. The present experiments aimed to go further, to determine whether secondorder odor learning exists in this model (CS2-CS1 pairing) and to examine whether first- and second-order memories remain dependent in the neonatal brain. To date, Debiec et al. (2006) showed in adult rats that following first-, then second-order conditioning, CS2 memory remains dependent of CS1 memory for its expression in the long-term. Since mechanisms which support learning present specificities in newborns (Wilson and Sullivan 1994; Languille 2010), we suspected that early memories could be less dependent on each other after formation based on chainlike associations.

We investigated these early memory processes ( $n=115$ neonates, from 32 females) and their sensitivity to the action of anisomycin (AN; $42 \mathrm{mg} / \mathrm{kg}$ i.p.; Aldrich) after reactivation. Like other authors, using other species-e.g., adults (for review, see Davis and Squire 1984; Desgranges et al. 2008; Merhav and Rosenblum 2008) and newborns (Gruest et al. 2004; Languille

\section{${ }^{3}$ Corresponding author.}

E-mail gerard.coureaud@u-bourgogne.fr; fax 33380681601.

Article is online at http://www.learnmem.org/cgi/doi/10.1101//m.2145111. et al. 2008, 2009), we defend that the blocking effect of AN on odor memory in newborn rabbits cannot be explained by an aversive effect but by amnesia (Coureaud et al. 2009). A first-order conditioning $(5 \mathrm{~min})$ with the odorant $\mathrm{E}$ (ethyl acetoacetate; Aldrich) + MP (2-methylbut-2-enal; Aldrich) was carried out in 1-d-old pups (described previously in Coureaud et al. 2006, 2009). A second-order conditioning was similarly conducted the day after by the pairing of CS2 (odorant EM or F, ethyl maltol or furaneol, respectively; Aldrich) + CS1 (odorant E). For reactivation, odorants $\mathrm{E}$ or $\mathrm{F}$ were presented alone for two minutes on day 3. Conditioning and reactivation occurred at 10:30 a.m., one hour before nursing, which happened only daily in this species (Zarrow et al. 1965). The behavioral assay consisted of, on day 4, a validated activation test (e.g., Schaal et al. 2003; Coureaud et al. 2006, 2008, 2009) during which the pup was immobilized in one hand of the experimenter, its head being left free, and the test odor was presented for $10 \mathrm{sec}$ with a glassstick $0.5 \mathrm{~cm}$ in front of the nares. The response was an on/off response; a test was considered positive when the stimulus elicited specific scanning movements of the head (vigorous, of low amplitude) displayed after stretching toward the stick and followed by labial seizing; nonresponding pups displayed no response except sniffing. Thus, the dependent variable was the proportion of pups displaying at least once the typical orocephalic behavior. Each pup participated in only one experiment but was successively tested to three stimuli (inter-trial interval of $120 \mathrm{sec}$; soft drying of the nose after positive response). The order of presentation of the stimuli was counterbalanced, except for the MP being always the last-presented (control). To avoid interference with their prandial state (Montigny et al. 2006), the pups were tested before sucking. To minimize litter effect, only two pups per litter were included in a given group. The percentages of pups responding to the stimuli were compared by the Cochran Q test or $\chi^{2}$ test of McNemar for dependent samples, and by the $\chi^{2}$ test of Pearson for independent groups, with Yates' correction when necessary. Data were regarded as significant when the tests (two-tailed) ended with $P<0.05$.

To determine whether a MP-learned odorant (CS1) promotes second-order odor learning, two groups of 1-d-old pups $(n=12$ / group) were first conditioned to the odorant $\mathrm{E}$ by exposure to the $\mathrm{E}+\mathrm{MP}$ blend, exposed on day 2 to CS2 + CS1 mixtures, i.e., to odorants EM + E (Group 1) or F + E (Group 2), and behaviorally 
tested on day 4. Nine other pups exposed to $\mathrm{E}+\mathrm{MP}$ on day 1 highly responded to $\mathrm{E}$ and MP on day 2 (>88.9\%). This level of conditioning, equivalent to that observed in previous studies (Coureaud et al. 2006, 2009), allowed us to consider that pups from Groups 1 and 2 have efficiently learned the odorant $\mathrm{E}$ before being conditioned to CS2 by pairing with odorant E. The Group 1 (Fig. 1A) highly responded to odorant EM, as Group 2 did after presentation of odorant $F$ (Fig. 1B; no difference between the stimuli: $\chi^{2}=0.54, P>0.05$ ). Thus, after pairing with odorant $\mathrm{E}$, the initially neutral EM and F odorants triggered responses in pups. Second-order conditioning was thus functional in newborn rabbits, independently of the chemical nature of CS2. The proportion of pups responding to CS2 on day 4 was similar to that of pups responding to $\mathrm{MP}\left(\chi^{2}<0.5, P>0.05\right)$, and pups from both groups responded as well to CS2 as to CS1 $\left(\chi^{2}<0.05, P>0.05\right)$. Thus, pups were able to build CS2-CS1 association after the initial association between CS1 and US (MP). Since similar results were obtained with our two pairs of CSs, we pursued our investigations only with odorants E-F as CS1-CS2.

To assess whether the second-order conditioning was really the consequence of an associative CS1-induced learning, 41 pups were distributed in three groups. Group 1 formed a positive control with pups conditioned to $\mathrm{E}+\mathrm{MP}$ on day 1 and to $\mathrm{F}+\mathrm{E}$ on day 2. In Groups 2 and 3, the respective exposure to $\mathrm{E}$ and $\mathrm{MP}$ or to $\mathrm{F}$ and $\mathrm{E}$ was successive $(2 \times 2.5 \mathrm{~min} /$ stimulus, $1 \mathrm{~min}$ of delay between the stimulations). Control pups highly and similarly responded to odorants $\mathrm{F}, \mathrm{E}$, and $\mathrm{MP}\left(\chi^{2}<0.05, P>0.05\right)$ (Fig. 2A). Pups from Group 2 responded only to the MP (comparisons of $\mathrm{F}$ or $\mathrm{E}$ vs. MP: $\chi^{2}=9.1, P<0.01$ ) (Fig. $2 \mathrm{~B}$ ). Thus, the absence of simultaneity in the exposure to $\mathrm{E}$ and MP prevented the learning of $\mathrm{E}$ and consequent learning of $\mathrm{F}$; this result underlined the associative nature of the first-order conditioning and suggested that $\mathrm{F}$ acquired the value of signal only when $\mathrm{E}$ previously became significant for neonates. Pups from Group 3 responded to $\mathrm{E}$ and to $\mathrm{MP}$ but not to $\mathrm{F}$ (E or MP vs. $\mathrm{F}: \chi^{2}=10.1$, $P<0.01$ ) (Fig. 2C); this finding highlighted the associative nature of the second-order conditioning.

Finally, to evaluate whether CS2 and CS1 odor memories remained linked after CS2-CS1 association, 41 pups were MPconditioned to odorant $\mathrm{E}$ on day 1, E-conditioned to odorant $\mathrm{F}$ on day 2, and then separated into three different groups. On day 3, pups from Group 1 (control) were submitted to a brief recall
A

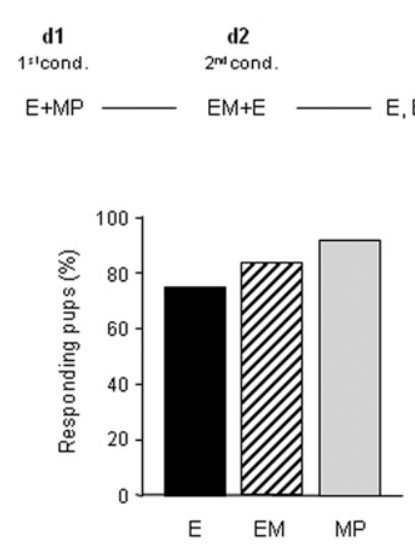

B
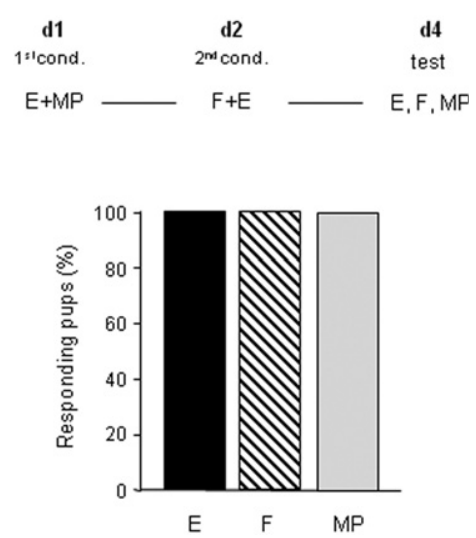

Figure 1. Second-order conditioning. Rabbit pups were first conditioned to odorant $E$ by pairing with the mammary pheromone (MP) on day 1 (d1). Then, they were conditioned to odorant EM $(A)$ or odorant $F(B)$ by pairing with odorant $E$ on $d 2$. The behavioral responses to $E, E M$, and $M P$ or to $E, F$, and MP were tested on $\mathrm{d} 4$. Pups highly respond to the first and the second conditioned stimuli, and similarly respond to the unconditioned one (MP). of odorant $\mathrm{F}$ before contiguous injection of saline. Pups from Group 2 were also cued with F but immediately injected with AN. Pups from Group 3 were re-exposed to odorant $\mathrm{E}$ before being injected with AN. The step of reconsolidation aimed to make the consolidated memory of CS2 or CS1 labile and therefore sensitive to amnesia induced by a pharmacological agent, such as AN (Nader et al. 2000a; Gruest et al. 2004; Languille et al. 2008; Coureaud et al. 2009). Consequently, it should allow determination of whether the disturbance of CS2 memory also impacted the memory of CS1 (and conversely, after amnesia of CS1). Tested on day 4, pups from the three groups strongly responded to MP (Fig. 3A-C), a result showing that neither the injection by itself nor the injected product disturbed the general physiology and behavior of the newborns. Moreover, pups from Group 1 strongly responded to odorants $\mathrm{F}$ and $\mathrm{E}$ (comparison $\mathrm{F}$ vs. E vs. MP: $\mathrm{Q}=2, \mathrm{df}=2, P=0.34$ ) (Fig. 3A). Thus, the saline injection after CS2 recall had no consequence on the CS2 and CS1 memories. On the contrary, AN injection after brief recall of CS2 was followed by complete amnesia of CS2 in pups from Group 2 (responsiveness to odorant $\mathrm{F}$ in Groups 2 vs. 1 : $\chi^{2}=25, P<$ $0.001)$ (Fig. 3B). Concurrently, these pups still responded to odorant E, as control pups did (Group 2 vs. Group 1: $\chi^{2}=0.06, P>$ 0.05). After recall of CS1 followed by AN injection, pups from Group 3 did not respond to CS1 but still responded to CS2 (responsiveness to odorants E vs. F: $\chi^{2}=8.1, P<0.01$ ) (Fig. 3C). Thus, amnesia concerned exclusively the CS1 in this group.

The present study highlights for the first time that secondorder conditioning is functional in rabbit pups. A new stimulus, initially neutral, acquires an attractive value when it is paired with another odorant previously associated with the MP. It may be surprising that an incompletely mature organism establishes such a high form of learning, including a CS2 which has never been directly associated with the primary reinforcer (MP, here) but which acquires its predictive value. However, complete sensory, cerebral, and cognitive maturity appears unnecessary for second-order conditioning. Cheatle and Rudy (1979) suggested second-order odor-aversive conditioning in 6-d-old rats, Miller et al. (1990) demonstrated odor-induced secondary aversion of texture in 4-d-old rats, and Cheslock et al. (2003) even showed that rats exhibit second-order olfactory conditioning three hours after birth. The present study confirms the functionality of this mnesic process in newborns from another species and provides original results concerning odor memories built in a chain and their link in the neonatal brain.

The associative aspect of CS1-induced odor learning is confirmed. Unpaired presentations of CS2 and CS1 or CS1 and MP (i.e., sensitization or generalization) failed to induce any conditioning. Thus, CS2 acquires a signal value only after simultaneous pairing with CS1, as CS1 after perceptual contingency with MP (Coureaud et al. 2009). Coherently, the formation of second-order memory strictly depends on pre-existing first-order conditioning (Rescorla 1980) following a chain of memories illustrated by $\mathrm{MP} \rightarrow \mathrm{CS} 1 \rightarrow \mathrm{CS} 2$. According to this chain, when CS2 acquires a positive value, this value does not alter the CS1 value, a suggestion coherent with the strong responsiveness displayed by pups to CS1 after CS1-induced learning of CS2. Moreover, second-order learning is generally supposed to be weaker than 
A

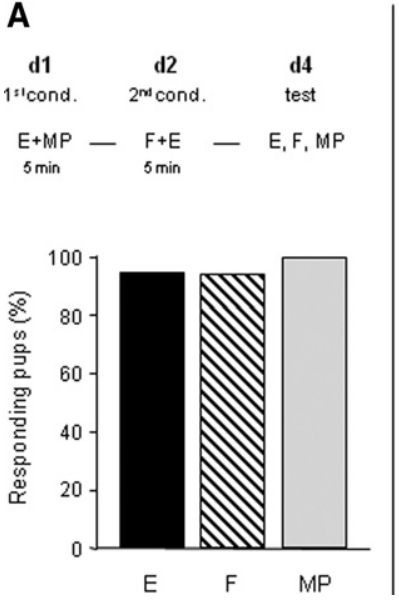

B

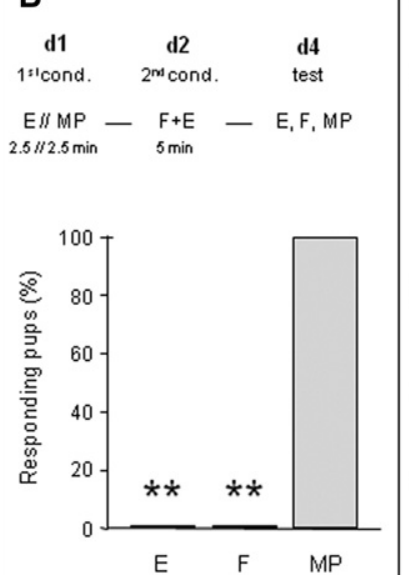

C
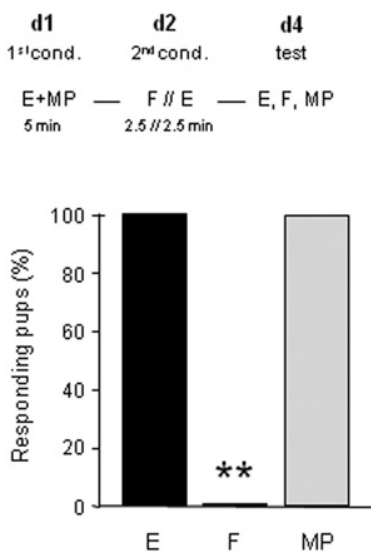

Figure 2. Associative nature of the second-order learning. (A) Pups were conditioned to odorant $\mathrm{E}$ by pairing with MP on day $1(\mathrm{~d} 1)$ and to odorant $\mathrm{F}$ by pairing with odorant $\mathrm{E}$ on $\mathrm{d} 2$ (Group 1). (B) Pups were successively exposed to odorant $\mathrm{E}$ and MP on $\mathrm{d} 1$ and simultaneously exposed to odorants $\mathrm{F}+\mathrm{E}$ on d2 (Group 2). (C) Pups were MP-conditioned to odorant E on d1 and then successively exposed to odorants $\mathrm{F}$ and $\mathrm{E}$ on $\mathrm{d} 2$ (Group 3). All the pups were tested for their responsiveness to odorants $\mathrm{E}$, $\mathrm{F}$, and MP on $\mathrm{d} 4$. Pups strongly respond to odorant $\mathrm{F}$ only after association with odorant $\mathrm{E}$, previously MP-learned. ${ }^{* *} P<0.01$

first-order (Rescorla 1980). Here, the responsiveness of pups is strong and similar both to CS2 and CS1. The strength of the second-order conditioning may be due to our paradigm, which involves a US of high biological value, close temporal proximity between CSs, and a single sensory modality (Gewirtz and Davis 2000). Taken together, these findings highlight that conditioned memories coexist, allowing both CS1 and CS2 to become predictive signals of a critical social event (nursing) and releasers of a decisive individual behavior (sucking).

Regarding the dependence of CS1 and CS2 memories, (1) the injection of AN after recall of CS2 is followed by amnesia of CS2. It demonstrates the effective reactivation of CS2 memory and, subsequently, the requirement of a reconsolidation process (new protein synthesis) for stabilization in the longer term (Sara 2000; Nader 2003; Dudai and Eisenberg 2004; Sara and Hars 2006). However, the recall of CS2 does not trigger (or only weakly triggers) the reactivation of CS1 memory, since this latter stays immune from the amnesic effect induced by AN. (2) When CS1 is recalled, the corresponding memory is reactivated and impaired by AN. This result confirms that MP-induced odor memory, like other kind of memories, needs reconsolidation (Coureaud et al. 2009). In addition, there is no bottomup reactivation from the first- to the second-order memory; impairment of CS1 memory occurring after consolidation of CS2 memory is selective and leaves the second memory immune from the abolishment of the first one. Thus, first- and second-order memories appear independent on postnatal day 4 , even if the formation of CS2 memory directly requires the previous formation of CS1 memory.

These results partially differ from those obtained in adult rats by Debiec

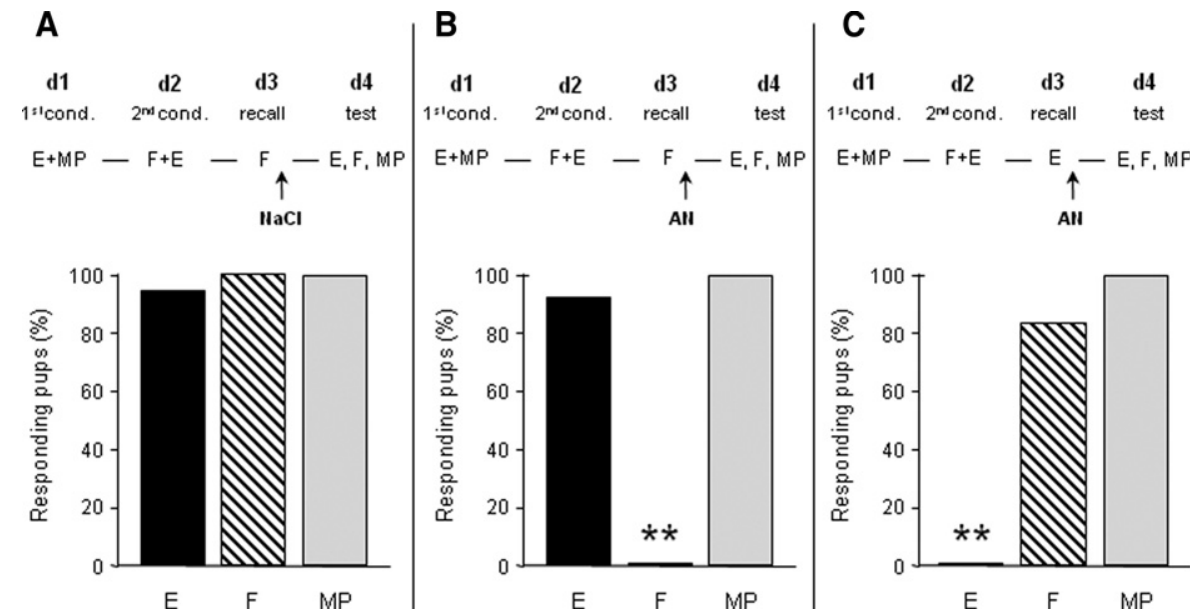

Figure 3. Reactivation of odor memories created by first- and second-order conditionings. Pups were conditioned to odorant $E$ by pairing with MP on day 1 (d1), and to odorant $F$ by pairing with odorant $E$ on $\mathrm{d} 2$. On $\mathrm{d} 3$, pups were reactivated by exposure to odorant $\mathrm{F}$ and, respectively, injected with saline (Group 1) (A) or anisomycin (AN, Group 2) (B), or were reactivated by exposure to odorant $\mathrm{E}$ and immediately injected with AN (Group 3) (C). All the pups were tested for their responsiveness to odorants $\mathrm{E}, \mathrm{F}$, and MP on d4. Post-reactivation administration of AN impairs only the conditioned response to the odorant used as the retrieval cue. ${ }^{* *} p<0.01$. 
different conditioned responses, and, on the other hand, similar responses may depend on different neural structures during ontogeny (Languille et al. 2009). Such variations could create differences in bonding of first- and second-order memories as a function of age. For instance, adults could establish a stronger link of causality between CS1 and CS2 as compared to newborns, making, therefore, CS2 more dependent on CS1.

Anyway, the long-term dependence of CS2-CS1 memories created by first-, then second-order conditionings does not appear as an absolute rule in mammals. Our result on CS1 retrieval is more in accordance with those observed in the odor aversion paradigm in the slug (Limax flavus), showing that cooling treatment administered after reactivation of first-order memory impairs the souvenir of CS1 but not of CS2 (Sekiguchi et al. 1997). However, these authors also observe that amnesic treatment administered after CS2 retrieval affects first- and second-order memories (Sekiguchi et al. 1994, 1997), suggesting that reactivation of CS2 may propagate to CS1 in this invertebrate (a result that differs from our results and those of Debiec et al. 2006).

In conclusion, the fact that CS2 and CS1 memories become rapidly independent in a context of chain odor learning could be particular to neonates. This independence could allow for high-order memories recently created to survive to erasure or modification of first-order ones, and thus for distinct acquired cues and significant rewards to remain connected. In newborns looking for maternal nipples and milk, who have to behave in an olfactory environment subjected to permanent variations, such rapid learning and independent retention of novel information may enlarge their knowledge about, and therefore improve their responsiveness and adaptation to, the environment.

\section{Acknowledgments}

We thank Valérie Saint-Giorgio, Florent Costilhes, Nicolas Malaty (Centre de Zootechnie, Université de Bourgogne, Dijon), and Brigitte Quennedey (CSGA, Dijon) for their technical contributions. All experiments were carried out in accordance with ethical rules enforced by French law and were supported by ethical committee authorization no. 2406. This work was financially supported by the CNRS.

\section{References}

Cheatle MD, Rudy JW. 1979. Ontogeny of second-order odor-aversion conditioning in neonatal rats. J Exp Psychol Anim Behav Process 5: 142-151.

Cheslock SJ, Varlinskaya EI, High JM, Spear NE. 2003. Higher order conditioning in the newborn rat: Effects of temporal disparity imply infantile encoding of simultaneous events. Infancy 4: 157-176.

Coureaud G. 2001. "Olfactory regulation of sucking in newborn rabbit: Ethological and chemical characterization of a pheromonal signal." PhD thesis, University Paris 13.

Coureaud G, Moncomble AS, Montigny D, Dewas M, Perrier G, Schaal B. 2006. A pheromone that rapidly promotes learning in the newborn. Curr Biol 16: 1956-1961.

Coureaud G, Thomas-Danguin T, Le Berre E, Schaal B. 2008. Perception of odor blending mixture in the newborn rabbit. Physiol Behav 95: 194-199.

Coureaud G, Languille S, Schaal B, Hars B. 2009. Pheromone-induced olfactory memory in newborn rabbits: Involvement of consolidation and reconsolidation processes. Learn Mem 16: 470-473.

Davis HP, Squire LR. 1984. Protein synthesis and memory: A review. Psychol Bull 96: 518-559.
Debiec J, Doyere V, Nader K, Ledoux JE. 2006. Directly reactivated, but not indirectly reactivated, memories undergo reconsolidation in the amygdala. Proc Natl Acad Sci 103: 3428-3433.

Desgranges B, Lévy F, Ferreira G. 2008. Anisomycin infusion in amygdala impairs consolidation of odor aversion memory. Brain Res 1236: $166-175$.

Dudai Y, Eisenberg M. 2004. Rites of passage of the engram: Reconsolidation and the lingering consolidation hypothesis. Neuron 44: $93-100$.

Gewirtz JC, Davis M. 2000. Using Pavlovian higher-order conditioning paradigms to investigate the neural substrates of emotional learning and memory. Learn Mem 7: 257-266.

Gruest N, Richer P, Hars B. 2004. Memory consolidation and reconsolidation in the rat pup require protein synthesis. J Neurosci 24: $10488-10492$.

Kim JH, Richardson R. 2010. New findings on extinction of conditioned fear early in development: Theoretical and clinical implications. Biol Psychiatry 67: 297-303.

Languille S. 2010. "Dynamics of memory during postnatal development, study in rat pup." PhD thesis, Editions Universitaires Européennes, Sarrebruck.

Languille S, Gruest N, Richer P, Hars B. 2008. The temporal dynamics of consolidation and reconsolidation decrease during post-natal development. Learn Mem 15: 434-442.

Languille S, Richer P, Hars B. 2009. Approach memory turns to avoidance memory with age. Behav Brain Res 202: 278-284.

McGaugh JL. 1966. Time dependent processes in memory storage. Science 153: $1351-1358$.

McGaugh JL. 2000. Memory-A century of consolidation. Science 287: $248-251$.

Merhav M, Rosenblum K. 2008. Facilitation of taste memory acquisition by experiencing previous novel taste is protein-synthesis dependent. Learn Mem 15: 501-507.

Miller JS, Molina JC, Spear NE. 1990. Ontogenetic differences in the expression of odor-aversion learning in 4 - and 8-day-old rats. Dev Psychobiol 23: 319-330.

Montigny D, Coureaud G, Schaal B. 2006. Rabbit pup response to the mammary pheromone: From automatism to prandial control. Physiol Behav 89: 742-749.

Moriceau S, Sullivan RM. 2005. Neurobiology of infant attachment. Dev Psychobiol 47: 230-242.

Nader K. 2003. Memory traces unbound. Trends Neurosci 26: 65-72.

Nader K, Schafe GE, LeDoux JE. 2000a. The labile nature of consolidation theory. Nat Rev Neurosci 1: 216-219.

Nader K, Schafe GE, Le Doux JE. 2000b. Fear memories require protein synthesis in the amygdala for reconsolidation after retrieval. Nature 406: $722-726$.

Raineki C, Shionoya K, Sander K, Sullivan RM. 2009. Ontogeny of odor-LiCl vs. odor-shock learning: Similar behaviors but divergent ages of functional amygdala emergence. Learn Mem 16: 114-121.

Rescorla RA. 1980. Pavlovian second order conditioning: Studies in associative learning. Erlbaum, Hillsdale, NJ.

Sara SJ. 2000. Retrieval and reconsolidation: Toward a neurobiology of remembering. Learn Mem 7: 73-84.

Sara SJ, Hars B. 2006. In memory of consolidation. Learn Mem 5: $515-521$.

Schaal B, Coureaud G, Langlois D, Ginies C, Semon E, Perrier G. 2003. Chemical and behavioral characterization of the rabbit mammary pheromone. Nature 424: $68-72$.

Sekiguchi T, Suzuki H, Yamada A, Mizukami AM. 1994. Cooling-induced retrograde amnesia reflexes Pavlovian conditioning associations in Limax flavus. Neurosci Res 18: 267-275.

Sekiguchi T, Yamada A, Suzuki H. 1997. Reactivation-dependent changes in memory states in the terrestrial slug Limax flavus. Learn Mem 4: $356-364$

Wilson DA, Sullivan RM. 1994. Neurobiology of associative learning in the neonate: Early olfactory learning. Behav Neural Biol 61: 1-18.

Zarrow MX, Denenberg VH, Anderson CO. 1965. Rabbit: Frequency of suckling in the pup. Science 150: 1835-1836.

Received January 19, 2011; accepted in revised form March 31, 2011. 


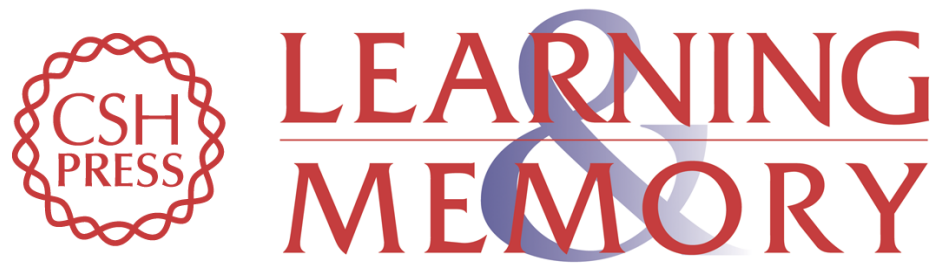

\section{Independence of first- and second-order memories in newborn rabbits}

Gérard Coureaud, Solène Languille, Virginie Joly, et al.

Learn. Mem. 2011, 18:

Access the most recent version at doi:10.1101//m.2145111

References This article cites 31 articles, 12 of which can be accessed free at: http://learnmem.cshlp.org/content/18/6/401.full.html\#ref-list-1

License

Email Alerting Receive free email alerts when new articles cite this article - sign up in the box at the Service top right corner of the article or click here. 